\title{
Desempenho de frangos de corte sob suplementação com ácidos lático, fórmico, acético e fosfórico no alimento ou na água
}

\author{
Eduardo Spillari Viola ${ }^{1}$, Sergio Luiz Vieira ${ }^{2}$, Cibele Araújo Torres ${ }^{1}$, Dimitri Moreira de \\ Freitas $^{3}$, Josemar Berres ${ }^{1}$
}

\footnotetext{
1 Programa de Pós-Graduação em Zootecnia - UFRGS, Porto Alegre - RS.

2 Departamento de Zootecnia - UFRGS, Porto Alegre - RS.

${ }^{3}$ Curso de graduação em Medicina Veterinária - UFRGS, Porto Alegre - RS.
}

RESUMO - Este estudo foi realizado para avaliar os efeitos da suplementação de ácidos orgânicos nas dietas e de ácidos orgânicos e ácido ortofosfórico na água de bebida sobre o desempenho de frangos de corte. Foram utilizadas 2.112 aves divididas em seis tratamentos, cada um com oito repetições. As dietas, exclusivamente vegetais, foram formuladas à base de milho e farelo de soja sem antibióticos ou anticoccidianos. A dieta controle não foi suplementada com ácidos orgânicos. As demais foram suplementadas com misturas de ácidos orgânicos, formuladas para cada fase de crescimento (1 a 7, 8 a 21 e 22 a 35 dias de idade): mistura A: ácidos lático (52\%), fórmico (1\%) e acético (2\%); mistura B: ácidos lático (76\%), fórmico (2\%) e acético (4\%); mistura C: ácidos lático (50\%), fórmico (8\%) e acético (7\%); mistura D: ácido fórmico (85\%). A mistura E continha 40\% de ácido lático, 5\% de ácido acético e 5\% de ácido ortofosfórico e foi adicionada à água de bebida. As doses adicionadas nas dietas, por fase, foram: 8,0; 4,5 e 2,5 kg/t para as misturas A, B e C e 2,5; 2,5 e 2,0 kg/t para a mistura D. A mistura E foi utilizada na água de bebida nas doses de 3,0;2,0;1,0 kg/1.000 L. O experimento foi conduzido em delineamento completamente casualizado. Houve um benefício geral da suplementação da mistura de ácidos sobre o ganho de peso das aves. Entretanto, não houve diferença na conversão alimentar ao final do estudo. O consumo de alimento foi menor para a mistura $\mathrm{B}$, enquanto o consumo de água foi negativamente afetado pela mistura E fornecida na água. O peso relativo das seções do intestino delgado aos 7 dias de idade foi menor nas aves da dieta controle, enquanto, aos 21 dias de idade, foi menor nas aves alimentadas com a dieta suplementada com as misturas A e C. A mistura E utilizada na água determinou redução no comprimento de jejuno aos 7 dias de idade, enquanto a mistura B teve efeito negativo sobre os comprimentos de íleo e intestino delgado aos 21 dias de idade. Em comparação à dieta controle, sem suplementação de antibióticos promotores de crescimento, as dietas suplementadas com acidificantes foram eficientes em melhorar o ganho de peso de frangos de corte.

Palavras-chave: ácidos orgânicos, dietas exclusivamente vegetais, nutrição animal

\section{Performance of broilers supplemented with blends of lactic, formic, acetic, and phosphoric acids in the feed or water}

\footnotetext{
ABSTRACT - This study was carried out to evaluate the effect of the supplementation of organic acids in the diets and ortho-phosphoric acid in the drinking water on broiler performance. A total of 2,112 broiler chicks was allotted to six treatments, each one with eight replications. The diets, all vegetable, were composed by corn-soybean meal without antibiotic growth promoters or anticoccidials. A control diet did not have organic acids, whereas the other treatments had supplementation of organic acid blends as follow for the feeding phases from 1 to 7, 8 to 21, and 22 to 35 days of age: blend A: lactic acid (52\%), formic (1\%) and acetic (2\%); blend B: lactic acid (76\%), formic (2\%) and acetic (4\%); blend C: lactic acid (50\%), formic (8\%) and acetic (7\%); blend D: formic acid (85\%). Blend E contained $40 \%$ of lactic acid, $5 \%$ of acetic acid and 5\% of ortho-phosphoric and was added to drink water. The added doses in diets, for phase, were: $8.0,4.5$, and $2.5 \mathrm{~kg} / \mathrm{t}$ for blends A, B and C and 2.5, 2.5, and $2.0 \mathrm{~kg} / \mathrm{t}$ for blend D. Blend $\mathrm{E}$ was used in drink water in doses of 3.0, 2.0, and 1.0 kg/1,000 L. A completely randomized design was used. There was a general benefit of the supplementation of the organic acid blend on weight gain of birds. However, no difference was observed for feed conversion at the end of the study. Feed intake was lower for birds fed blend B, whereas water intake was reduced by the blend $\mathrm{E}$ added to the drinking water. Relative weight of small intestines sections at 7 days of age was smaller in the birds on the control diet, while at the 21 days of age, was smaller in the birds supplemented with blends A and C. The blend E used in the water determined a reduction in the jejunum length at 7 days of age, while blend $B$ had negative effects on the ileum and small intestine lengths at 21 days of age. In comparison to the control diet, without supplementation of growth promoters antibiotics, the diets supplemented with organic acids were efficient in improving the weight gain of broilers.
}

Key Words: all vegetable diets, animal nutrition, organic acids 


\section{Introdução}

Programas de alimentação têm incluído o fornecimento de antibióticos em doses subterapêuticas e constantes para melhorar o desempenho zootécnico de animais domésticos. Esses antibióticos utilizados tradicionalmente são conhecidos como promotores de crescimento. Essa prática, entretanto, tem sido questionada por consumidores preocupados com a resistência microbiana a esses medicamentos. Em janeiro de 2006, a Comunidade Européia proibiu o uso dos promotores de crescimento em rações para animais destinados ao consumo humano (EC, 2003) e, como conseqüência, alternativas a estes aditivos têm sido estudadas visando à disponibilização de produtos que substituam esses antibióticos no mercado.

Diversos ácidos orgânicos, principalmente na forma de misturas, têm sido estudados e propostos recentemente. Os ácidos orgânicos de cadeia curta possuem atividade antimicrobiana e alguns, como o fórmico, acético, propiônico, butírico, láctico, cítrico e fumárico, são utilizados na nutrição animal há alguns anos (Cherrington et al., 1991; Dibner \& Buttin, 2002). Ácidos inorgânicos também têm sido propostos como parte de misturas com ácidos orgânicos, como o fosfórico (Van Immerseel et al., 2004).

O uso de ácidos orgânicos é mais largamente aceito na criação para suínos, principalmente durante o desmame. Vários efeitos têm sido relacionados ao uso desses aditivos, como o tamponamento gástrico e a ativação enzimática (Cranwell, 1995; Partanen, 2001), a retenção do conteúdo gástrico (Ravindran \& Kornegay, 1993), o controle bacteriano e estímulo da secreção pancreática (Harada et al., 1988). O estímulo da proliferação celular no intestino delgado (Sakata, 1987; Sakata, 1988) e do metabolismo intermediário (Eidelsburger, 2001) também são relatados e resultam em melhor utilização da energia e da proteína.

A atividade antimicrobiana dos ácidos orgânicos está relacionada à redução do pH e à capacidade de penetração na célula microbiana livremente através da membrana celular, liberando íons e prótons e alterando o pH intracelular e o gradiente de concentração iônica (Cherrington et al., 1991; Russel, 1992). Em seqüência, ocorrem elevação da força iônica e aumento da pressão sobre a parede do microrganismo, levando-o à morte (Rodriguez-Palenzuela, 2000). Mecanismos de adaptação e resistência a ambientes ácidos, entretanto, também são apresentados para diferentes ácidos orgânicos e inorgânicos gerando resistência a bactérias gram-positivas e gram-negativas (Foster, 1999; Merrell \& Camilli, 2002).

Valores de $\mathrm{pH}$ dos segmentos intestinais das aves não são constantes e apresentam médias de 6,4 no duodeno,
6,6 no jejuno e 7,2 no íleo (Sturkie, 1986). Assim, os ácidos orgânicos com mais de um $\mathrm{pK}_{\mathrm{a}}$ ou a utilização de misturas de ácidos orgânicos com vários $\mathrm{pK}_{\mathrm{a}}$ potencialmente mantêm sua atuação em maior extensão intestinal. Em aves, o uso de ácidos orgânicos tem como principal objetivo a ação antimicrobiana no trato gastrointestinal. Além disso, por possuírem valor energético, também favorecem a nutrição animal.

Resultados contraditórios têm sido relatados sobre a suplementação com ácidos orgânicos em dietas para frangos de corte, possivelmente em razão das diferenças no seu modo de ação, da condição ambiental, da dose utilizada e das respostas avaliadas. A suplementação de ácido cítrico ou ácido fumárico demonstrou melhora no desempenho e na utilização de fósforo da dieta (Patten \& Waldroup,1988; Snow et al., 2004; Rafacz-Livingston et al., 2005a; RafaczLivingston et al., 2005b). Todavia, em outros trabalhos esse efeito não foi observado (Izat et al., 1990a, Henrique et al., 1998). Os ácidos propiônico e butírico reduziram, enquanto os ácidos fórmico ou acético aumentaram a colonização por Salmonella enteritidis (Van Immerseel et al., 2004). A adição de níveis crescentes de ácido propiônico resultou em diminuição da colonização de Escherichia coli no intestino delgado (Izat et al., 1990b). Os ácidos acético, propiônico e butírico têm ação trófica sobre a estrutura e o desenvolvimento intestinais, aumentando o tamanho dos vilos e a superfície de absorção (Sakata, 1987; Leeson et al., 2005).

Objetivou-se com este trabalho avaliar o efeito da inclusão de diferentes misturas de ácidos orgânicos nas dietas e de ácidos orgânicos e inorgânicos na água de bebida sobre o desempenho e as características de peso e comprimento de intestino delgado de frangos de corte.

\section{Material e Métodos}

O experimento foi conduzido nas instalações do Aviário Experimental da Estação Experimental Agronômica da Universidade Federal do Rio Grande do Sul (UFRGS), BR 290, km 147, Eldorado do Sul, Rio Grande do Sul. Foram alojados 2.112 frangos de corte machos de 1 dia de idade do cruzamento Cobb x Cobb 500, com peso inicial de $44 \pm 0,20 \mathrm{~g}$, provenientes de matrizes de 36 semanas de idade. As aves foram mantidas em 48 boxes com dimensões de $175 \times 150 \mathrm{~cm}$, totalizando 44 aves por boxe, e vacinadas contra Marek, Bouba e Gumboro no incubatório. Aos 21 dias de idade, foi realizada a remoção das aves com problemas de aprumos, as fêmeas e os refugos de todos os boxes. O lote foi conduzido com práticas de manejo usuais na produção comercial. 
A cama foi reutilizada após criação de dois lotes consecutivos de frangos de corte. O aquecimento foi realizado com campânulas a gás, de forma a manter a temperatura ambiente em $32^{\circ} \mathrm{C}$ nos primeiros dois dias. Nos dias seguintes, a temperatura foi reduzida em $1^{\circ} \mathrm{C}$ a cada dois dias até atingir a temperatura de conforto das aves nos limites das condições de ambiente natural da época. Água e alimento foram fornecidos ad libitum aos animais durante todo o período experimental. O programa de luz adotado foi de 24 horas até os 14 dias e de 18 horas até o final do período experimental. As temperaturas máxima e mínima foram mensuradas diariamente.

As dietas experimentais, exclusivamente vegetais, foram formuladas à base de milho e farelo de soja, não continham anticoccidiano ou antibióticos promotores de crescimento e foram compostas de modo que os nutrientes e a energia fossem iguais ou superiores ao recomendado por Rostagno et al. (2000).

As aves alimentadas com a dieta controle não receberam suplementação de ácidos. As demais receberam suplementação de ácidos orgânicos e inorgânicos, fornecidos nas fases de 1 a 7,8 a 21 e de 22 a 35 dias de idade. As misturas de ácidos adicionadas às dietas para cada fase foram as seguintes: mistura A: 52 \% lático, $1 \%$ fórmico e 2\% acético; mistura B: 76\% lático, 2\% fórmico e 4\% acético; mistura C: 50\% lático, 8\% fórmico e 7\% acético; mistura D: 85\% fórmico. A mistura $\mathrm{E}$ foi composta de $40 \%$ lático, 5\% acético e $5 \%$ ortofosfórico, adicionada à água de bebida em tratamento em que as aves consumiram dieta sem ácidos (Tabela 1). As misturas foram fornecidas por fase nas respectivas doses: 8,$0 ; 4,5$ e 2,5 kg/t para as misturas A, B e C e 2,5; 2,5 e 2,0 kg/t para a mistura D. A mistura E foi adicionada na água de bebida nas doses de 3,0; 2,0 e $1,0 \mathrm{~kg} / 1.000 \mathrm{~L}$ (Tabela 2).

Os valores de energia metabolizável (EM) (Tabela 1), obtidos a partir de estimativas de Eidelsburger (2001), foram utilizados na formulação das dietas (Tabela 3), enquanto os de fósforo, presentes apenas no ácido ortofosfórico na mistura E, não foram considerados.

As aves foram pesadas em grupos por boxe aos 1, 7, 21 e 35 dias de idade. As dietas experimentais foram pesadas e fornecidas no início de cada uma das fases e as sobras de cada fase foram coletadas ao final das fases pré-inicial, inicial e de crescimento. O peso das aves mortas foi registrado diariamente e posteriormente utilizado para correção do cálculo da conversão alimentar.

O consumo aparente de água foi estimado para cada fase do período experimental utilizando-se um reservatório plástico com capacidade de $20 \mathrm{~L}$, graduado em mL, colocado na saída do cano de distribuição de água e acoplado na
Tabela 1 - Proporção de acidificantes (\%) nas misturas utilizadas e seus valores de $\mathrm{P}$ disponível (\%) e EM (kcal/kg)

\begin{tabular}{lccccc}
\hline Item & \multicolumn{5}{c}{ Mistura } \\
\cline { 2 - 6 } & A & B & C & D & E \\
\hline & Pó & \multicolumn{4}{c}{ Líquido } \\
\hline Ácido láctico & 52,00 & 76,00 & 50,00 & - & 40,00 \\
Ácido fórmico & 1,00 & 2,00 & 8,00 & 85,00 & - \\
Ácido acético & 2,00 & 4,00 & 7,00 & - & 5,00 \\
Ácido ortofosfórico & - & - & - & - & 5,00 \\
Veículo & 45,00 & 18,00 & 35,00 & 15,00 & 50,00 \\
P disponível & - & - & - & - & 1,60 \\
EM & 2.000 & 2.900 & 2.120 & 1.180 & 1.770 \\
\hline
\end{tabular}

${ }^{1}$ Produto líquido: água; produto em pó: sílica + água.

Tabela 2 - Quantidades de misturas de acidificantes utilizados na composição das dietas, em kg/t (misturas A, B, C e D) ou L/1.000 L de água (mistura E)

\begin{tabular}{|c|c|c|c|c|c|c|}
\hline \multirow[t]{2}{*}{ Dieta } & \multirow[t]{2}{*}{ Controle } & \multicolumn{5}{|c|}{ Mistura } \\
\hline & & A & B & $\mathrm{C}$ & $\mathrm{D}$ & E \\
\hline $\begin{array}{l}\text { Pré-inicial } \\
\text { (1 a } 7 \text { dias) }\end{array}$ & - & 8,0 & 8,0 & 8,0 & 2,5 & 3,0 \\
\hline $\begin{array}{l}\text { Inicial } \\
\text { (7 a } 21 \text { dias) }\end{array}$ & - & 4,5 & 4,5 & 4,5 & 2,5 & 2,0 \\
\hline $\begin{array}{l}\text { Crescimento } \\
\text { (21 a } 35 \text { dias) }\end{array}$ & - & 2,5 & 2,5 & 2,5 & 2,0 & 1,0 \\
\hline
\end{tabular}

Tabela 3 - Composição da dieta controle negativo

\begin{tabular}{|c|c|c|c|}
\hline \multirow[t]{2}{*}{ Ingrediente (\%) } & \multicolumn{3}{|c|}{ Idade das aves (dias) } \\
\hline & 1 a 7 & 8 а 21 & 22 a 35 \\
\hline Milho & 55,05 & 58,04 & 62,73 \\
\hline Farelo de soja $45,5 \%$ & 38,68 & 34,51 & 28,79 \\
\hline Fosfato bicálcico & 1,70 & 1,69 & 1,53 \\
\hline Calcário & 1,13 & 1,07 & 1,00 \\
\hline L-Lys & 0,13 & 0,16 & 0,13 \\
\hline DL-Met & 0,21 & 0,20 & 0,14 \\
\hline L-Thr & 0,04 & 0,02 & 0,38 \\
\hline Sal & 0,38 & 0,38 & 0,02 \\
\hline Bicarbonato de sódio & 0,25 & 0,11 & 0,06 \\
\hline Cloreto de colina & 0,03 & 0,03 & 0,21 \\
\hline Caulim & 0,16 & 0,03 & 0,01 \\
\hline Óleo de soja & 2,04 & 3,56 & 4,80 \\
\hline Premix vitamínico* & 0,10 & 0,10 & 0,10 \\
\hline Premix mineral** & 0,10 & 0,10 & 0,10 \\
\hline \multicolumn{4}{|c|}{ Composição nutricional (\%) } \\
\hline EM (kcal/kg) & 2.900 & 3.050 & 3.180 \\
\hline PB & 22 & 20 & 18 \\
\hline $\mathrm{Ca}$ & 0,99 & 0,95 & 0,87 \\
\hline $\mathrm{P}$ disponível & 0,45 & 0,44 & 0,40 \\
\hline K & 0,90 & 0,83 & 0,74 \\
\hline $\mathrm{Na}$ & 0,24 & 0,20 & 0,18 \\
\hline Lys digestível & 1,18 & 1,10 & 0,94 \\
\hline Met + Cys digestível & 0,84 & 0,78 & 0,67 \\
\hline Thr digestível & 0,77 & 0,69 & 0,59 \\
\hline
\end{tabular}

* Composição por kg de ração: Vit A: 8.000 UI; Vit $D_{3}: 2.000$ UI; Vit E 30 UI; Vit K: 2 mg; Tiamina: 2 mg; Riboflavina: 6 mg; Piridoxina: 2,5 mg; Cianocobalamina: 0,012 mg; Ácido pantotênico: 15 mg; Niacina: 35 mg; Ácido fólico: $1 \mathrm{mg}$; Biotina: 0,08 mg; Colina: $1.500 \mathrm{mg}$.

** Composição por kg de ração: Fe: 40 mg; Zn: 80 mg; Mn: 80 mg; Cu: $10 \mathrm{mg}$; l: 0,7 mg; Se: 0,3 mg. 
entrada de cada bebedouro. Tanto a entrada do sistema como sua saída foram controladas por meio de torneiras. Os bebedouros foram limpos diariamente mediante a retirada de resíduos de cama e de outras sujidades. Antes de ser descartada, a água presente no bebedouro foi recolhida; os resíduos de cama e ração foram separados utilizando-se peneira de 0,05 mesh. O volume de água medido em proveta com capacidade para $1 \mathrm{~L}$ e graduação de $10 \mathrm{~mL}$ foi considerado perda diária de água. Ao final de cada fase, o consumo de água foi estimado pela soma dos volumes fornecidos, subtraídos dos volumes perdidos e do restante no reservatório de água. O consumo médio diário foi estimado pela divisão desse total pelo número médio ponderado de aves vivas em cada fase.

Nos dias 7 e 21 de idade das aves, uma ave com peso representativo de cada boxe (média $\pm 1 / 2$ desvio-padrão) foi sacrificada por deslocamento cervical e pesada. O intestino delgado foi removido e o duodeno, o jejuno e o íleo foram isolados com uso de fio cirúrgico. As secções foram imediatamente seccionadas, esvaziadas por meio de cuidadosa pressão com os dedos polegar e indicador e secas com papel absorvente para medida do comprimento com régua e pesagem.

O experimento foi conduzido em delineamento completamente casualizado, com seis tratamentos e oito repetições por tratamento. Os dados foram submetidos à análise de variância utilizando-se o módulo General Linear Models (GLM) do programa estatístico Statistical Analysis System (SAS, 2001) a 5\% de probabilidade para diferenças significativas. As variáveis que apresentaram diferença estatística foram submetidas ao teste de médias Tukey.

Foram avaliadas as respostas ao ganho de peso, consumo de ração, conversão alimentar corrigida paea mortalidade, consumo de água, peso e comprimento relativos do intestino delgado e de suas secções.

\section{Resultados e Discussão}

Houve um benefício geral do uso das misturas sobre o ganho de peso corporal no período total (Tabela 4). O uso das misturas D na ração e E na água promoveu ganho de peso superior em relação ao obtido com a mistura $\mathrm{C}$ e a dieta controle no período de 1 a 7 dias de idade. Na fase de 8 a 21 dias de idade, todas misturas de ácidos foram iguais entre si e superiores ao tratamento controle. No período de 22 a 35 dias, no entanto, a mistura $\mathrm{D}$ promoveu ganho superior ao obtido com as misturas E e A e não diferiu do obtido com as misturas B e C e com a dieta controle. Entre as misturas de ácidos utilizadas, a C e D proporcionaram melhores resultados no período total, em comparação à controle.
A suplementação das misturas de ácidos teve efeito sobre a conversão alimentar apenas no período de 8 a 21 dias (Tabela 4), quando foi pior para as aves alimentadas com a dieta controle e a mistura E.

Tabela 4 - Desempenho e consumo de água de frangos de corte sob suplementação de ácidos orgânicos na dieta e de ácidos orgânicos e fosfórico na água ${ }^{1,2}$

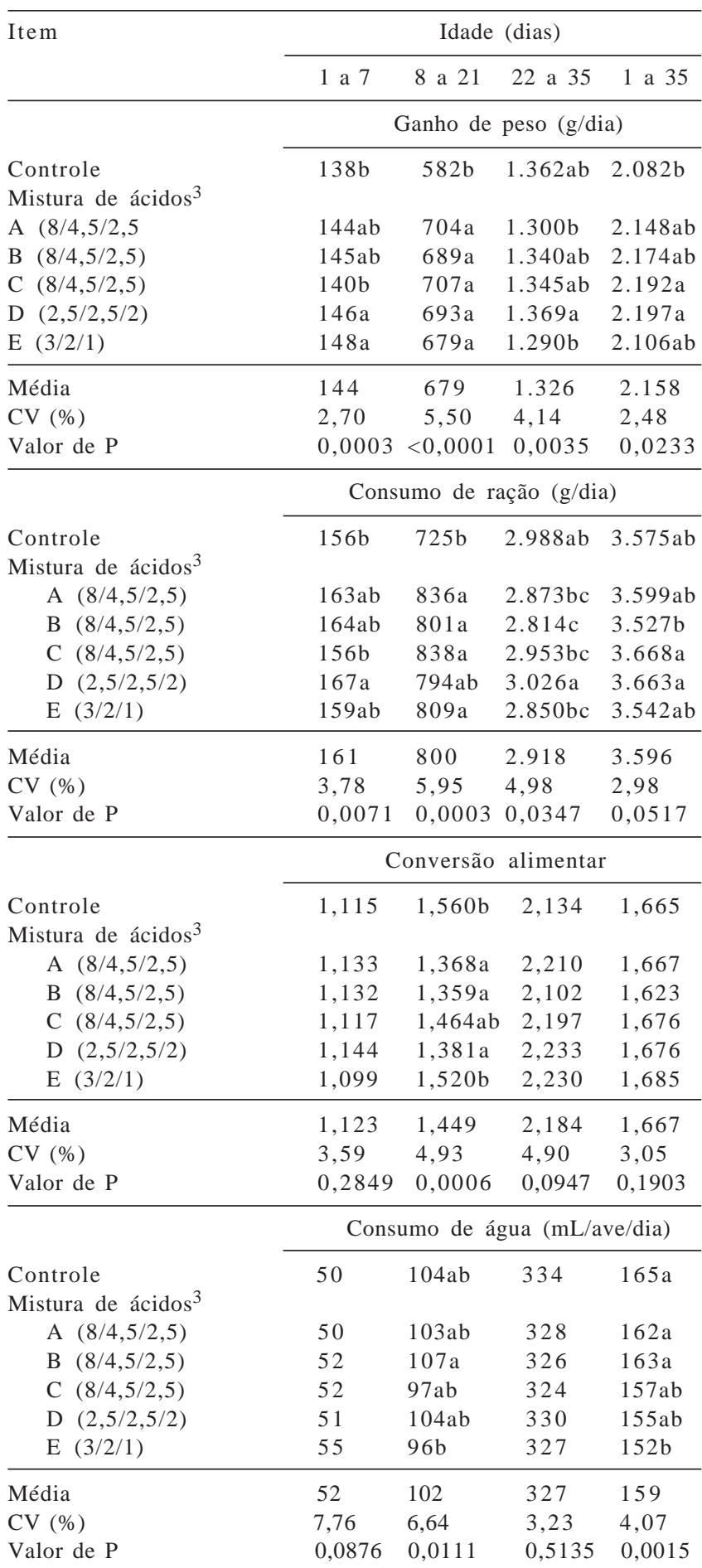

${ }^{1}$ Mistura E adicionada na água, todas as demais no alimento.

2 Médias seguidas de letras diferentes na mesma coluna diferem entre si pelo teste Tukey.

3 Valores entre parênteses após o tratamento representam doses nas fases pré-inicial/inicial/crescimento $(\mathrm{kg} / \mathrm{t})$. 
O consumo de água no período de 8 a 21 dias de idade foi inferior para a mistura $\mathrm{E}$ em relação à mistura $\mathrm{B}$, sendo os demais tratamentos semelhantes a estes e entre si. Já no período total, de 1 a 35 dias de idade, o consumo de água foi novamente inferior para a mistura E, porém em relação às misturas A, B e ao tratamento controle, sendo as misturas C e D semelhantes a todos os tratamentos.

O uso de ácidos orgânicos e inorgânicos com o objetivo de substituir os antibióticos promotores de crescimento em dietas para frangos de corte tem aumentado. A redução da carga de microrganismos é a principal função atribuída a esses medicamentos, portanto, são esperados efeitos na prevenção de alterações digestivas e conseqüente melhoria na conversão alimentar, no ganho de peso e na digestibilidade (Anderson et al., 1999). Entretanto, os ácidos orgânicos possuem uma miríade mais ampla de efeitos esperados se comparados aos antibióticos. Enquanto os efeitos do antibióticos se limitam à ação antimicrobiana, os efeitos dos ácidos dependem de sua composição. Além das capacidades antimicrobianas, dependendo da dosagem os ácidos orgânicos atuam sobre o metabolismo intermediário. O ácido fórmico é importante na transferência de unidades de um carbono, mas seu acúmulo no organismo pode levar à toxidez (Johlin et al., 1987; Lehninger et al., 1993). O ácido láctico serve de fonte de energia para as células após a pronta conversão em glicose e o ácido acético é uma fonte de energia para a célula após alterações pelo ciclo dos ácidos tricarboxílicos (Partanen \& Mroz, 1999).

De modo geral, os ácidos orgânicos utilizados nas doses e combinações deste estudo não tiveram efeito negativo ou prejudicial sobre o desempenho dos animais. Em estudos anteriores, o uso do ácido lático foi seguro, inclusive quando utilizado em doses altas (Zobac et al., 2004). O ácido fórmico, por sua vez, apresenta metabolismo de eliminação mais lenta do organismo e pode acumular e levar ao aparecimento de quadros de intoxicação em mamíferos; sua eliminação está relacionada à presença de níveis adequados de ácido fólico na dieta dos animas (Johlin et al., 1987), característica provavelmente relacionada aos resultados erráticos obtidos com o uso de misturas contendo ácido fórmico (Patten \& Waldroup, 1988; Denli et al., 2003). Neste estudo, o ganho de peso e o consumo de alimento melhoraram com o uso de ácidos orgânicos no alimento e da mistura desses ácidos com o ácido fosfórico na água de bebida. Entretanto, os benefícios obtidos ao final do estudo foram relacionados à melhora no ganho de peso, diferentemente das melhorias preferencialmente obtidas na conversão alimentar quando usados antibióticos promotores de crescimento.
O peso relativo do intestino delgado, do duodeno e do jejuno aos 7 dias de idade nas aves alimentadas com a dieta controle foi inferior ao daquelas sob suplementação com as misturas de ácidos (Tabela 5). Aos 21 dias de idade, entre as secções do intestino delgado, apenas o duodeno apresentou diferenças. A mistura $\mathrm{E}$ foi semelhante à mistura $\mathrm{C}$ e promoveu maior peso em relação às demais. Aos 7 dias de idade, o jejuno das aves que receberam a mistura E apresentou o menor comprimento e, nas demais, com exceção daquelas que receberam a mistura $\mathrm{A}$, foi semelhante ao otido no tratamento controle. Aos 21 dias de idade, o comprimento do intestino delgado foi menor nas aves que receberam a mistura $\mathrm{B}$ em relação às misturas $\mathrm{D}$ e $\mathrm{E}$ e à dieta controle e não diferiu entre as aves que receberam as misturas A e C (Tabela 6). A mistura C proporcionou menor comprimento de jejuno em relação à dieta controle. Os resultados obtidos com as demais misturas foram similares entre si. O comprimento do íleo aos 21 dias de idade foi maior nas aves que receberam a mistura $\mathrm{D}$ em relação àquelas alimentadas com a dieta controle, que apresentaram valor superior ao obtido com mistura B. As misturas $\mathrm{C}$ e $\mathrm{E}$ não diferiram da mistura D e da dieta controle, assim como a mistura A foi semelhante à dieta controle e à mistura $\mathrm{B}$.

A presença de ácidos graxos de cadeia curta no intestino estimula a secreção de muco alcalino e provoca danos à parede intestinal com a redução do tamanho de vilosidades (Vattay et al., 1988; Shimotoyodome et al., 2000). Essa secreção tem efeito de proteção das paredes intestinais contra a abrasão provocada pelo fluxo da digesta e dificulta a colonização das paredes pelas bactérias, reduzindo sua presença no meio. Alguns ácidos também apresentam efeito estimulador na proliferação de enterócitos, efeito trófico que resulta em aumento da massa intestinal e melhora da capacidade de absorção dos nutrientes (Sakata, 1987). O aumento da massa do intestino delgado em resposta aos ácidos orgânicos, bem como o maior comprimento do intestino delgado aos 7 dias de idade, comprova maior relação peso:comprimento das seç̧ões do intestino delgado. Esse aumento da massa intestinal pode ser decorrente do aumento de alteração no tamanho das vilosidades e da profundidade de criptas de Lieberkuhn. O aumento na capacidade de absorção de nutrientes obtida com o benefício destas modificações justifica o benefício em ganho de peso obtido com o uso de ácidos orgânicos e fosfórico.

\section{Conclusões}

A suplementação com misturas de ácidos orgânicos contendo ácidos lático, fórmico e acético no alimento e o 
Tabela 5 - Peso relativo das secções do intestino delgado aos 7 e 21 dias de idade de frangos de corte sob suplementação com misturas de ácidos orgânicos na dieta e de ácidos orgânicos e fosfórico na água (\% peso vivo) ${ }^{1,2}$

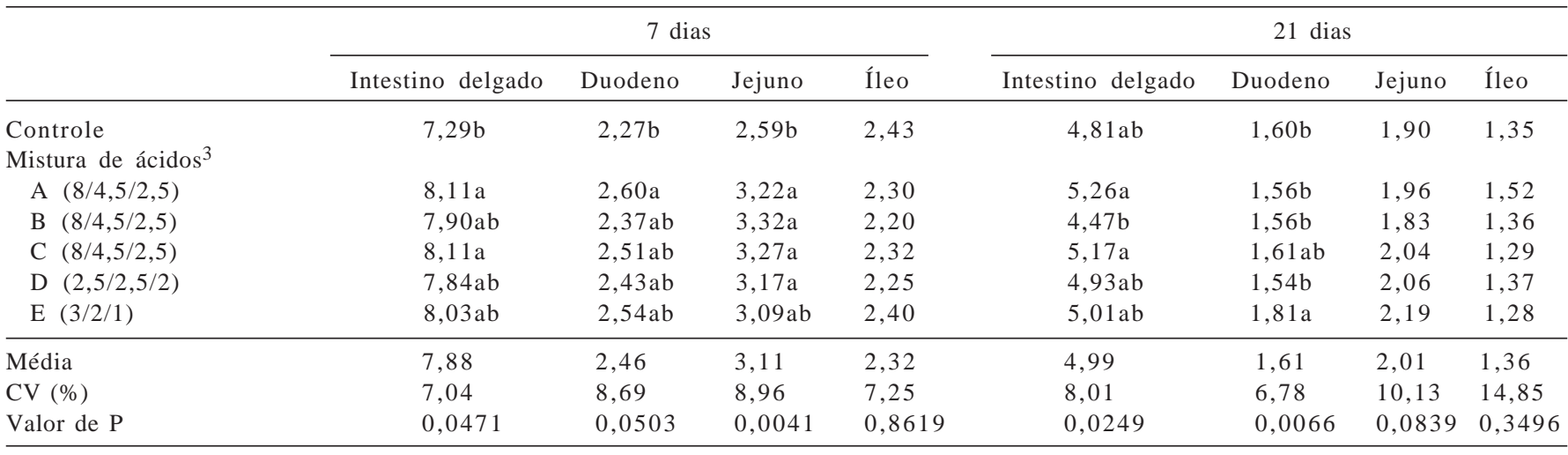

1 Mistura E adicionada à água e todas as demais, ao alimento.

2 Médias seguidas de letras diferentes na mesma coluna diferem entre si pelo teste Tukey.

${ }^{3}$ Valores entre parênteses após o tratamento representam doses nas fases pré-inicial/inicial/crescimento (kg/t).

Tabela 6 - Comprimento das secções do intestino delgado aos 7 e 21 dias de idade sob suplementação com misturas de ácidos orgânicos na dieta e de ácidos orgânicos e fosfórico na água $(\mathrm{cm})^{1,2}$

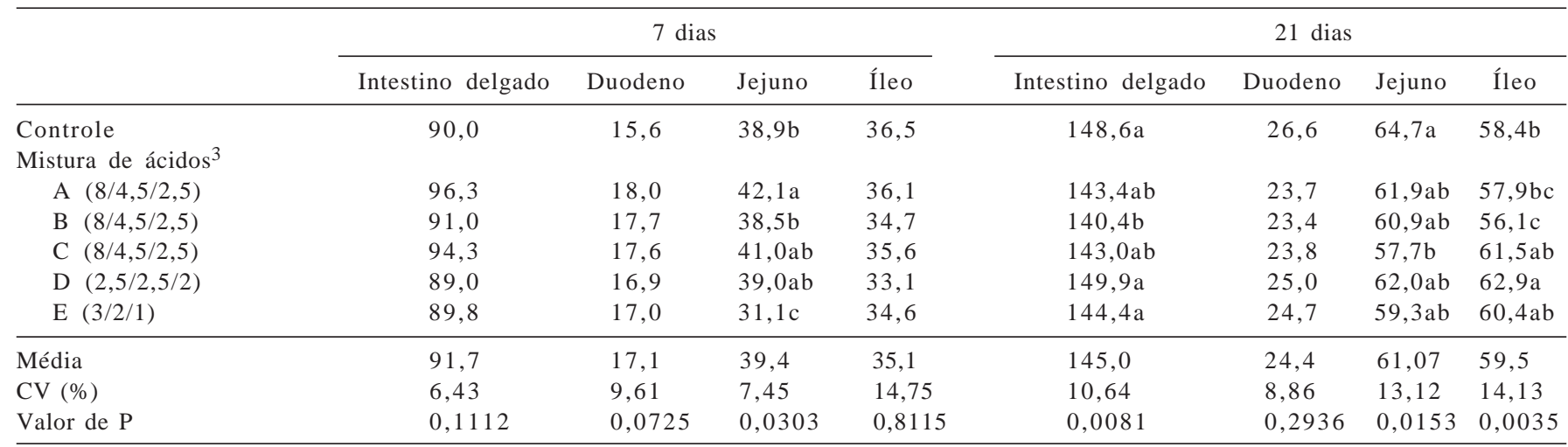

${ }^{1}$ Mistura E adicionada à água e todas as demais, ao alimento.

2 Médias seguidas de letras diferentes na mesma coluna diferem entre si pelo teste Tukey.

${ }^{3}$ Valores entre parênteses após o tratamento representam doses nas fases pré-inicial/inicial/crescimento $(\mathrm{kg} / \mathrm{t})$.

fornecimento destes ácidos com ácido fosfórico na água melhoram o ganho de peso de frangos de corte em comparação ao uso de dietas isentas de antibióticos promotores de crescimento.

\section{Literatura Citada}

ANDERSON, D.B.; MCCRACKEN, V.J.; AMINOV, R.I. et al. Gut microbiology and growth-promoting antibiotics in swine. Pig News and Information, v.20, p.115N-122N, 1999.

CHERRINGTON, C.A.; HINTON, M.; CHOPRA, I. Organic acids: chemistry, antibacterial activity and practical applications. Advances Microbiological Physiology, v.32, p.87-108. 1991.

CRANWELL, P.D. Development of the neonatal gut and enzyme systems. In: VALEY, M.A. (Ed.) The neonatal pig: development and survival. Wallingford/CAB Iternational, 1995. p.99-154.

DENLI, M.; OKAN, F.; ÇELIK, K. Effect of dietary probiotic, organic acid and antibiotic supplementation to diets on broiler performance and carcass yield. Pakistan Journal of Nutrition, v.2, n.2, p.89-91. 2003.
DIBNER, J.J.; BUTTIN, P. Use of organic acids as a model to study the impact of gut microflora on nutrition and metabolism. Journal of Applied Poultry Research, v.11, p.453-463, 2002.

EIDELSBURGER, U. Feeding short-chain fatty acids to pigs. In: GARNSWORTHY, P.C.; WISEMAN, J. (Eds.) Recent developments in pig nutrition 3. Nottingham: Nottingham University Press, 2001. p.107-121.

FOSTER, J.W. When protons attack: microbial strategies of acid adaptation. Current Opinion in Microbiology, v.2, p.170174. 1999.

HARADA, E.; KIRIYAMA, H.; KOBAYASHI, E. et al. Postnatal development of biliary and pancreatic exocrine secretion in piglets. Comparative Biochemistry and Physiology, v.91A, p.43-51, 1988.

HENRIQUE, A.P.F.; FARIA, D.E.; FRANZOLIN, R. et al. Efeito de ácido orgânico, probiótico e antibiótico sobre o desempenho e rendimento de carcaça de frangos de corte. In: REUNIÃO ANUAL DA SOCIEDADE BRASILEIRA DE ZOOTECNIA, 35. 1998, Botucatu. Anais... Botucatu: Sociedade Brasileira de Zootecnia, 1998. (CD-ROM).

IZAT, A.L.; TIDWELL, N.M.; THOMAS, R.A. et al. Effects of buffered propionic acid in diets on the performance of broiler 
chickens and on microflora of the intestine and carcass. Poultry Science, v.69, p.818-826, 1990a.

IZAT, A.L.; ADAMS, M.H.; CABEL, M.C. et al. Effects of formic acid or calcium formate in feed on performance and microbial characteristics of broilers. Poultry Science, v.69, p.876-1882, 1990b.

JOHLIN, F.C.; FORTAMN, C.S.; NGHIEM, D.D. et al. Studies on the role of folic acid and folate-dependent enzymes in human methanol poisoning. Molecular Pharmacology, v.31, p.557$561,1987$.

LEESON, S.; NAMKUNG, H.; ANTONGIOVANNI, M. et al. Effect of butiric acid on the performance and carcass yield of broiler chickens. Poultry Science, v.84, p.1418-1422, 2005.

LEHNinger, A.L.; NELSON, D.A.; COX, M.M. Principles of biochemistry. New York: Worth Publishers, 1993. 1013p.

MERREL, D.S.; CAMILLI, A. Acid tolerance of gastrointestinal pathogens. Current Opinion in Microbiology, v.5, p.5155, 2002.

PARTANEN, K. Organic acids - their efficacy and modes of action in pigs. In: PIVA, A.; KNUDESEN, K.E.B.; LINDBERG, J.E. (Eds.) Gut environment of pigs. Nottingham: Nottingham University Press, 2001. p.201-217.

PARTANEN, K.; MROZ, Z. Organic acids for performance enhancement in pig diets. Nutrition Research Reviews, v.12, n1, p.117-145, 1999.

PATTEN, J.D.; WALDROUP, P.W. Use of organic acids in broiler diets. Poultry Science, v.67, p.1178-1182, 1988.

RAFACZ-LIVINGSTON, K.A.; PARSONS, C.M.; JUNGKT, R.A. The effects of various organic acids on phytate phosphorus utilization in chicks. Poultry Science, v.84, p.1356-1362, 2005a.

RAFACZ-LIVINGSTON, K.A.; MARTINEZ-AMEZCUA, C.; PARSONS, C.M. et al. Citric acid improves phytate phosphorus utilization in crossbred and commercial broiler chicks. Poultry Science, v.84, p.1370-1375, 2005b.

RAVINDRAN, V.; KORNEGAY, E.T. Acidification of weaner diets: a review. Journal of the Science of Food and Agriculture, v.62, p.1880-1886, 1993.

RODRIGUEZ-PALENZUELA, P. Los ácidos orgânicos como agentes antimicrobianos. In: CURSO DE ESPECIALIZACIÓN FEDNA: Avances in Nutrición y Alimentación Animal, 16., 2000, Barcelona. Proceedings... Barcelona: 2000. p.155-167.

ROSTAGNO, H.S. Tabelas brasileiras para aves e suínos: composição de alimentos e exigências nutricionais, 2000. 141p.
RUSSELL, J.B. Another explanation for the toxicity of fermentation acids at low $\mathrm{pH}$ : anion accumulation versus uncoupling. Journal of Applied Bacteriology, v.73, p.363-370, 1992.

STATISTICAL ANALYSIS SYSTEM - SAS. SAS/STAT user guide: Statistics Release. Cary: 2001. (CD-ROM)

SHIMOTOYODOME, A.; MEGURO, S.; HASE, T. et al. Short chain fatty acids but not lactate or succinate stimulate mucus release in the rat colon. Comparative Biochemistry and Physiology, Part A, v.125, p.525-531, 2000.

SAKATA, T. Stimulatory effect of short-chain fatty acids on epithelial cell proliferation in the rat intestine: a possible explanation for trophic effects of fermentable fiber, gut microbes and luminal trophic factors. British Journal of Nutrition, v.58, n.95, p.95-103, 1987.

SAKATA, T. Chemical and physical trophic effects of dietary fibre on the intestine of monogastric animals. In: BURACZEWSKA, L.; BURACZEWSKI, S.; PASTUSZEWSKA, B. et al. (Eds.) Digestive physiology in the pig. Jablonna: Polish Academy of Sciences, 1988. p.128-135.

SNOW, J.L.; BAKER, D.H.; PARSONS, C. Phytase, citric acid, and 1-á-hidroxycholecalciferol improve phytate phosphorus utilization in chicks fed a corn-soybean meal diet. Poultry Science, v.83, p.1187-1192, 2004.

STURKIE, P.D. Avian physiology. 4.ed. New York: SpringerVerlag, 1986. 516p.

THE EUROPEAN PARLIAMENT AND THE COUNCIL OF THE EUROPEAN UNION - EC. Regulation n.1831/2003 of 22 September 2003 on additives for use in animal nutrition. Office Journal, Berlin, v.192, p.0034-0034. Disponível em: http:// www.eu.intsga_doc?smartapi!celexapi!prod!CELEXnumbdoc\& numdoc $=32001 \mathrm{~L} 0029 \&$ model $=$ guichett $\& \mathrm{lg}=$ en $-101 \mathrm{k}$. Acesso em: 29/4/2004.

Van IMMERSEEL, F.; FIEVES, V.; BUCK, J. et al. Microencapsulated short-chain fatty acids in feed modify colonization and invasion early after infection with Salmonella enteritidis in young chickens. Poultry Science, v.83, p.69-74, 2004.

VATTAY, P.; FEIL, W.; KLIMESCH, S. et al. R. Acid stimulated secretion in the rabbit duodenum is passive and correlates with mucosal damage. Gut, v.29, p.284-290, 1988.

ZOBAC, P.; KUMPRECHT, I.; SUCHY, P. et al. Influence of L-lactic acid on the efficacy of microbial phytase in broiler chickens. Czech Journal of Animal Science, v.49, n.10, p.436-443, 2004. 